\title{
The Phonological Similarity Pattern of Words Contributing to Expressive Vocabulary in 18- to 36-Month-Old Toddlers
}

\author{
Yoonhee Yang, Suyeon Park, Ye Eun Hong, Suyeon Lee, Dongsun Yim \\ Department of Communication Disorders, Ewha Womans University, Seoul, Korea
}

Correspondence: Dongsun Yim, PhD Department of Communication Disorders, Ewha Womans University, 52 Ewhayeodae-gil, Seodamun-gu, Seoul 03760, Korea

Tel: $+82-2-3277-6720$

Fax: $+82-2-3277-2122$

E-mail: sunyim@ewha.ac.kr

Received: April 2, 2019

Revised: May 24, 2019

Accepted: June 3, 2019

This work was supported by the National Research Foundation of Korea Grant funded by the Korean Government in 2016 (No. NRF-

2016K2A9A2A19939734).
Objectives: In this study, the Korean MacArthur-Bates Communicative Development inventory (K M-B CDI), a standardized parent-report questionnaire, was used for analyzing the vocabulary development phonological similarity pattern of 18- to 36-month-old toddlers. Methods: We investigated the extent to which phonological similarity explains the expressive vocabulary according to the time differences in Experiment 1 and the group characteristics in Experiment 2. In Experiment 1, a total of 18 toddlers aged 18-36 months participated in this study. In Experiment 2, a total of 151 toddlers (typically developing children $[T D]=134$, late talkers $[L T]=17$ ) participated. Phonological similarity scores were calculated depending on the similarity rate between two words. Phonological similarity was divided into three conditions and defined as P1 (66\%), P2 (75\%), and P3 (80\%). We obtained overall expressive vocabulary and phonological similarity through the K M-B CDI. Results: In Experiment 1, P1, which shares relatively fewer phonemes between words, seems to be the best predictor of overall expressive vocabulary consistently. In Experiment 2 , all the phonological similarity conditions explained the overall expressive vocabulary scores in the TD group, but P1 was a significant explaining factor for expressive vocabulary in LT group. Conclusion: Although expressive vocabulary increased sharply, P1, which shares relatively fewer phonemes between words, consistently appeared to be the best predictor of overall expressive vocabulary. At least until the age of three, words with low phonological similarity are more easily distinguished, and this ability also seems to contribute to expressive vocabulary.

Keywords: 18- to 36-month-old toddlers, Phonological similarity, Late talkers, Expressive vocabulary, KM-B CDI
일반적으로 유아들은 약 $10-13$ 개월 사이에 첫 낱말을 산출하고, 18 -24개월에는 어휘폭발기(word spurt)가 시작되어 산출할 수 있 는 낱말의 수가 급격하게 증가하고 약 50 개의 어휘를 산출할 수 있 게 되는 것으로 보고된다(Fenson et al., 1994). 한국판 맥아더-베이 츠 의사소통발달 유아용(18-36개월) 목록으로 살펴본 결과, 아동 들은 18 개월에 평균 73-78개, 24개월에 249-308개, 30개월에 360415개, 36개월에 496-501개의 어휘를 사용하는 것으로 나타났다 (Pae \& Kwak, 2011). 또한, $\mathrm{Ha}$ 와 $\mathrm{Pi} \mathrm{(2018)의} \mathrm{연구에서도} \mathrm{18-23개월}$ 에 해당하는 아동들은 50 개 미만의 표현어휘를 보이다가 24 개월
이후에 표현어휘수가 폭발적으로 증가하는 것이 관찰되었다. 이를 통해, 6개월이라는 짧은 간격 차에도 아동의 어휘량이 빠르게 증가 하는 것을 확인할 수 있다. 초기 유아기의 어휘습득에 단어 빈도 (word frequency), 길이(word length), 그리고 밀도(word density) 또는 유사도(similarity) 등이 영향을 미칠 수 있다(Stokes, 2010; Storkel, 2004). 즉, 유아를 둘러싼 사람들이 많이 사용하는 고빈도 단어의 경우 저빈도 단어보다 더욱 빨리 습득하고 산출하게 되며, 단어의 길이가 긴 단어에 비해 짧은 단어의 경우 아동은 더 빨리 습 득하고 사용할 수 있다. 그러나, 단어의 밀도 또는 단어의 음운학적 
유사도와 관련된 연구결과는 대상자의 연령, 어휘의 수용(이해) 또 는 표현능력에 따라 상당히 다양한 양상을 보인다.

단어의 밀도는 음운학적 유사성에 근거하며, 어린 유아들의 생 산적인 어휘력 확장 및 어휘 처리에 상당히 중요한 요소로 간주된 다(Carlson, Sonderegger, \& Bane, 2014; Stokes, Bleses, Basbøll, \& Lambertsen, 2012). 일반적으로 선행연구에서는 단어의 밀도를 추 출하는 방법으로 음운이웃밀도를 사용한다. 음운이웃밀도(phonological neighborhood density)란, 하나의 음소를 추가, 삭제, 도 는 대체함으로써 구별되는 단어들의 수를 계산한 것을 말한다 (Luce \& Pisoni, 1998). 흔히 어린 유아가 어휘학습을 할 때는 저밀 도 단어에 비해 고밀도 단어가 더욱 빨리 습득되는 것으로 알려져 있다(Stokes, 2010; Storkel, 2004). Dollaghan (1994)의 연구에서도 부모가 보고하는 체크리스트를 통해 어린 유아가 알고 있는 단어 의 특징들을 조사한 결과, 단어의 $84 \%$ 가 적어도 하나 이상의 음운 론적으로 유사성을 지닌 단어를 가지고 있으며, 이는 초기 어휘들 이 음운적으로 밀도가 높은 특징을 지님을 시사한다. 친숙한 음소 들로 구성된 단어는 어린 유아들이 그 단어와 매우 유사한 새로운 단어를 활성화할 수 있게 하기 때문이다(Stokes et al., 2012).

특히 연령이 증가할수록, 어휘학습 경험이 증가하고, 음운 세부 사항을 듣는 데 더욱 집중하게 만들어 목표어휘와 비목표어휘 간 구별을 가능하게 하여 효과적으로 어휘를 습득하게 된다(Storkel, 2009; Werker, Fennell, Corcoran, \& Stager, 2002). Storkel (2004)은 약 8-30개월 사이의 유아를 대상으로 한 맥아더-베이츠 의사소통 발달 목록의 단어를 사용한 데이터베이스를 통해 가장 초기에 배 운 어휘의 특성을 조사하였다. 그 결과, 어린 유아들이 조기에 습득 한 단어일수록 이웃을 많이 가지고 있고, 나중에 습득한 단어일수 록 이웃을 적게 가지고 있음을 확인하였다. 즉, 연령이 증가하면서 점차 어휘집(lexicon)의 크기가 확장됨에 따라 그 효과는 점차 감소 하면서 음운 유사도가 낮은 단어도 쉽게 배울 수 있게 된다(Storkel, 2009). Stoel-Gammon (2011)은 2세 6개월까지의 어린 유아들은 어 휘습득에 있어서 어휘적 요인보다는 음운론적 요소에 더 큰 영향 을 받으며, 4 세까지 어휘와 음운 사이에 양방향적 연결이 존재한다 고 보고하였다. 그러나, Werker 등(2002)의 연구에서는 만 14 개월 의 아주 어린 유아의 경우 오히려 비슷한 소리를 내는 어휘를 변별 해내지 못하여 음운유사도가 높은 고밀도 조건의 도움을 받지 못 했으며, 18-24개월에 이르게 되어서야 음운적으로 유사한 단어를 학습할 수 있었다. 즉, 연령이 증가하고 어휘의 크기(vocabulary size)가 커지면서 점차음운적으로 유사한 단어들을 세부적인 특성 에 따라 분류하는 작업을 겪게 되는데, 예를 들어, 'big'이라는 단어 를 인식하고 표현하고자 할 때 아동은 'big'과 유사한 단어인 'bag', 'bug', 'dig' 등의 어휘들과 차별화되는 세부적인 표현을 하게 되는 것이다. 이처럼 18 개월 이후의 유아는 어휘 간 음운 세부정보의 변 별이 가능하여 이 능력을 정교화시켜 새로운 어휘를 학습하는 데 도움을 받을 수 있게 되고, 특히 새로운 어휘를 더 잘 배우는 아동 은 어휘학습시 세부적인 음운정보까지 주의를 집중할 수 있다.

그러나, 또 다른 선행연구에서는 음운학적으로 유사하게 들리는 낱말들이 많은 경우 표현어휘 습득에는 오히려 방해가 될 수 있음 을 언급하기도 하였다(Gahl \& Strand, 2016; Storkel, Armbrüster, \& Hogan, 2006). 말소리로 표현된 어떤 단어가 음운적으로 유사한 이웃단어를 많이 가지고 있을 경우 표현어휘력을 습득할 때에는 간 섭 작용을 보일 수 있다는 것이다. 아동들은 흔히 발음이 비슷한 서 로 다른 낱말을 구별하여 말할 때 힘들어 하는 경우가 있다. 예를 들어, ‘치킨'을 '키친'이라 말하거나, '토끼'를 ‘코끼(이)'라고 말하는 오류가 언어발달 과정상에서 흔하게 나타난다. 이는 아동의 불완 전한 음운 표상과 유사한 단어를 표현할 때의 조음상의 어려움에 근거할 수 있다(Choi, Kim, \& Kim, 2014; Ha \& Pi, 2018). Jarvis, Merriman, Barnett, Hanba와 Van Haitsma (2004)도 만 2세의 아 동은 음운적으로 유사한 두 낱말(기존 낱말, 기존 낱말과 유사한 새로운 가상 낱말)을 구별해야 하는 과제에서 음운적 유사성에 쉽 게 현혹되어 제시된 가상 낱말과 기존 낱말과 구별하는 것에 더욱 취약하였음을 보고하였다. 이처럼 초기 유아기 표현어휘력 측면에 서는 고빈도, 저밀도 낱말이 먼저 습득된다고 보고되기도 하였다 (Kim, 2014).

한편, 18-36개월 사이의 아동들 중 일부는 감각손상, 신경학적 결함, 혹은 인지적인 결함이 없음에도 언어발달, 특히 표현어휘력이 현저히 느린 경우가 있다. 이 아동들을 흔히 '말늦은 아동(late talker)'이라고 부른다(Hawa \& Spanoudis, 2014; Rescorla \& Alley, 2001). 이 아동들의 느린 언어발달은 지각적 결핍이론(perceptual deficit theory, PDT)에 따르면, 지각적 음운손상으로 인한 것으로 볼 수 있다(Joanisse \& Seidenberg, 2003). PDT는 저하된 음운지각이 빈 약한 음운작업기억에 영향을 주고, 안정적인 언어적 표상을 형성 하는 아동의 능력에 결함을 줄 수 있다고 본다. 다양한 선행연구에 서도 정교한 음운처리 능력을 보여주는 아동들이 음운처리를 잘 못하는 아동보다 더 견고한 언어능력을 보였다는 증거를 제시하였 다(Benasich \& Tallal, 2002; Guttorm et al., 2005; Kuhl et al., 2007; Rivera-Gaxiola, Klarman, Garcia-Sierra, \& Kuhl, 2005). 만 2세경 '말늦은 아동'이었던 유아들의 대다수는 만 3-4세경 정상 범주에 속하게 되지만, 학령기 이후의 구문 및 읽기 수준이 정상 범주아래 에 위치하는 것으로 보고되기도 하므로 이들에 대한 언어적 측면 에서의 조기개입이 어떻게 이루어져야 하는지 보다 세부적인 연구 
결과를 필요로 한다(Paul, 1996; Rescorla, 2002; Stokes, 2010).

국내에서는 $\operatorname{Kim}$ (2005)의 연구에서 만 4-5세 아동을 대상으로 낱말 간 음운적 유사성에 주목하여 기존 낱말과 음운적으로 전혀 다르거나 또는 음운적으로 유사한 가상 낱말을 이용한 빠른연결 (fast-mapping) 과제를 실시하였다. 그 결과, 단순언어장애(specific language impairment, SLI) 아동이 또래 일반아동 집단과 비교하 여 빠른연결능력을 설명하는 상호배제의 원칙(mutual exclusivity principle)의 전략적 활용에 있어서는 차이가 없었으나, 낱말의 음 운적 유사성에 가장 취약하였음을 보고하였다. 즉, 낱말 유사성이 높아지는 것에 비례하여 이름이 비슷한 친숙한 사물을 선택하는 비율이 증가한 것이다. 이는 SLI 아동들이 음운적 유사성에 쉽게 현 혹되어 자신이 들은 낱말이 전혀 새로운 단어였음을 깨닫지 못했기 때문인 것으로 설명하였다. 이는 SLI 아동이 기존 낱말에 대해 어휘 음운적 표상능력이 상대적으로 취약하거나, 음운인식능력이 제한 되어 있거나, 작업기억능력이 부족한 것에서 비롯될 수 있다(Gathercole \& Baddeley, 1990). 그러나, 이 연구에서는 어휘의 이해(수용) 측면에서 단어를 학습할 때 음운적 유사성이 미칠 수 있는 영향력 을 살펴본 연구로, 음운적 유사성이 표현어휘 측면에서는 어떠한 기 여를 하였는지 설명하지는 않아 관련 연구의 필요성이 제기된다.

이처럼 음운과 관련된 능력이 어린 아동의 어휘능력에 매우 중요 한 요소임을 확인하였음에도 불구하고, 영어와 한국어의 언어적으 로 다른 특성으로 인해 영어권에서 주로 이루어진 음운이웃밀도 또는 음운유사도 연구결과를 우리나라 아동의 어휘 양상에 단순 적용하기 어려운 측면도 있었다(Lee, Lee, \& Park, 1995; Song, Nam, $\&$ Koo, 2012; Stokes et al., 2012). 첫 번째로는, 한국어와 영어 간 자 음과 모음의 수가 다르고, 그 결과로 나오는 자음과 모음의 조합 양 상과 비율, 음운구조 등이 다르다는 것이다. 두 번째로는, 만 3세 이 전의 유아들의 어휘력과 어휘 유사도를 측정하기 위한 것이었으므 로, 적은 어휘 크기 속에서 음운적으로 유사한 단어들을 찾아야 하는 어려움이 있었다. 이에 본 연구에서는 단어 간 음운적 유사성 의 양상을 살펴보고, 얼마나 많이 음운을 공유하고 있는지를 계산 한 결과에 따라 단어의 음운유사도를 3 가지 유형으로 나누었을 때 유아들의 총 표현어휘력 점수를 가장 잘 설명하는 유형이 무엇인지 확인하기 위해 연구 1 과 연구 2 로 나누어 시행하였다. 본 연구에서 의 음운유사도(phonological similarity)의 조작적 정의는, 두 단어 간 음소 공유수를 단어의 전체 음소수로 나눈 값을 말하며, 음소 공유수는 단어의 전체 음소수와 하나의 음소만을 달리하여 서로 다른 단어로 구별되는 특성을 지닌다. 연구 1 에서는 추적연구 참여 를 희망한 18-36개월에 속하는 아동의 시간 차(T1-T2)에 따른 음 운유사도 양상을 확인하고, $\mathrm{T} 1, \mathrm{~T} 2$ 각 시점에서의 총 표현어휘력 점
수를 가장 잘 설명하는 초기(T1)의 음운유사도 유형을 확인하고자 하였으며, 연구 2에서는 만 18-36개월에 속하는 말늦은 아동 및 또 래 일반아동 집단 각각의 음운유사도 양상을 확인하고, 각 집단의 총 표현어휘력 점수를 가장 잘 설명하는 유형을 알아보고자 하였 다. 이에 대한 세부적인 연구질문은 다음과 같다.

$1-1)$ 만 18-36개월 유아 $(\mathrm{N}=18)$ 의 음운유사도는 약 8개월 간격을 둔 T1-T2 시점에 따라 어떠한 차이를 보이는가?

$1-2)$ 만 $18-36$ 개월 유아 $(\mathrm{N}=18)$ 의 초기(T1) 시점의 음운유사도 점수 중 어떤 유형이 $\mathrm{T} 1$ 과 $\mathrm{T} 2$ 각각의 표현어휘력을 가장 잘 설명해 주는가?

2-1) 만 18-36개월의 일반아동 $(\mathrm{N}=134)$ 과 말늦은 아동 $(\mathrm{N}=17)$ 의 음운 음운유사도 양상에 어떠한 특성을 보이는가?

$2-2)$ 만 $18-36$ 개월의 일반아동 $(\mathrm{N}=134)$ 과 말늦은 아동 $(\mathrm{N}=17)$ 각각의 표현어휘력을 가장 잘 설명해 주는 음운유사도는 무 엇인가?

\section{연구방법}

\section{연구 1}

연구대상

연구 1 에서는 만 $18-36$ 개월의 총 18 명(남 =9, 여=9)의 유아들이 참여하였다. 모든 유아들은 (1) 인지능력(Developmental assessment for the Early Intervention Program Planning, DEP; Jang, $\mathrm{Seo}, \& \mathrm{Ha}, 2011)$ 이 -1 SD 이상으로 정상 범주에 속하고, (2) 시청각 을 포함한 감각적인 어려움이 없고, (3) 부모로부터 현재 언어능력, 행동패턴, 활동 선호도, 그리고 가족력에 대한 보고를 받아 이상이 없음을 확인하였다. 아동은 평균적으로 약 8개월의 간격을 두고 두 번 검사에 참여하였다. 즉, T1 (time 1)은 처음 검사에 참여한 시 점을 뜻하며, T2 (time 2)는 두 번째 검사에 참여한 시점을 뜻한다. 따라서 연령의 경우 $\mathrm{T} 1$ 시점에서 아동의 평균연령은 22.89 개월이 었으며, T2 시점에서 아동의 평균연령은 31.11 개월로 차이가 유의 하였고 $(p<.01)$, 모두 36 개월 이하에 해당하였다. 인지능력은 $\mathrm{T} 1$ 시 점에서 111.11 점으로 $\mathrm{T} 2$ 시점의 111.72 점과 통계적으로 차이가 유 의하지 않았으나 $(p>.05), \mathrm{CDI}$ 표현어휘와 문법 점수는 두 시점 간 차이가 통계적으로 유의하였다 $(p<.05)$. 즉, $\mathrm{T} 1$ 시점에서 표현어휘 점수는 139.06 점이었으나, $\mathrm{T} 2$ 시점에서는 375.83 점으로 크게 증가 하였다. 문법 점수는 $\mathrm{T} 1$ 시점에서 12.78 점이었으나 $\mathrm{T} 2$ 시점에서는 42.67점으로 유의하게 증가하였다. 세부적인 내용은 Table 1에 제 시하였다. 
Table 1. Participants' characteristics

\begin{tabular}{|c|c|c|c|c|c|c|}
\hline & \multicolumn{3}{|c|}{ Experimental 1} & \multicolumn{3}{|c|}{ Experimental 2} \\
\hline & $\mathrm{T} 1(\mathrm{~N}=18)$ & $\mathrm{T} 2(\mathrm{~N}=18)$ & $t$ & $\mathrm{LT}(\mathrm{N}=17)$ & $\mathrm{TD}(\mathrm{N}=134)$ & $t$ \\
\hline Age (mo) & $22.89(3.07)$ & $31.11(2.89)$ & $31.304^{* *}$ & $23.35(4.49)$ & $27.39(6.47)$ & $2.50^{*}$ \\
\hline Nonverbal $1 \mathrm{O}^{\mathrm{a}}$ & $111.11(6.68)$ & $111.72(8.55)$ & .278 & $112.24(6.41)$ & 112.21 (8.99) & .012 \\
\hline Expressive vocabulary ${ }^{b}$ & $139.06(175.80)$ & $375.83(183.70)$ & $6.154^{* *}$ & 39.00 (48.63) & 365.64 (193.14) & $15.99 * *$ \\
\hline Grammar $^{b}$ & $12.78(21.31)$ & $42.67(26.72)$ & $5.838^{* *}$ & 7.88 (18.28) & 34.89 (26.47) & $5.41^{* *}$ \\
\hline
\end{tabular}

Values are presented as mean (SD).

$\mathrm{T} 1$ = time 1, T2 = time 2; LT = late talkers; $\mathrm{TD}$ = typically developing children.

aDevelopmental assessment for the Early Intervention Program planning (DEP).

${ }^{b}$ Korean MacArthur-Bates Communicative Development Inventories (K M-B CDI).

${ }^{*} p<.05,{ }^{* *} p<.01$.

\section{연구자료}

단어의 음운유사성(phonological similarity)

본 연구의 음운유사성 단어목록의 설정 기준은 표준화된 부모 보고 설문지인 '맥아더-베이츠 의사소통발달 평가(Korean MacArthur-Bates Communicative Development Inventories, K M-B CDI'의 18-36개월 대상의 유아용 설문지를 활용하였다. 언어병리 학전공 석사과정학생 3 명, 박사과정학생 1 명이 641 개 단어목록 중 2 음절 길이의 단어들을 모두 선별해 국립국어원 표준국어대사전 국제음성기호(IPA)에 맞게 전사한 후, 음소배열을 통해 3 개의 음소 중 2 개, 4 개의 음소 중 3 개, 그리고 5 개의 음소 중 4 개가 일치하는 단 어 각각 10 쌍을 발췌하였다.

총 3 가지 음운유사성 유형의 음운 공유 비율 설정이 타당한지 살 펴보기 위해 확인적 요인분석을 실시한 결과, 표본의 적절성을 측 정하는 $\mathrm{KMO}$ 값이 .784, Bartlett의 구형성 검정 통계값이 643.194 ( $p=.000)$ 로서 적합하며, .7 이상의 요인부하량을 나타내는 유형을 해당 요인에 포함되는 것으로 판단할 때 세 가지 요인으로 분류하 는 것이 타당하다고 볼수 있다.

본 연구에서 사용된 단어의 음운유사성은 총 3 가지 유형으로 두 단어 간 얼마나 음운적으로 유사한지, 얼마나 많은 음운을 공유하 고 있는지를 비율(\%)로 계산하여 $\mathrm{P} 1$ 은 $66 \%, \mathrm{P} 2$ 는 $75 \%, \mathrm{P} 3$ 은 $80 \%$ 를 공유하는 것으로 정의하였다. 즉, $\mathrm{P} 1$ 에는 두 단어의 자모음이 총 3 개의 음소 중 2 개인 약 $66 \%$ (예: $\mathrm{CVV}$ 끼워-미워, $\mathrm{VCV}$ 오리-우리), $\mathrm{P} 2$ 에는 두 단어의 자모음이 총 4 개의 음소 중 3 개인 약 $75 \%$ (예: $\mathrm{CVCV}$ 다리-다시), $\mathrm{P} 3$ 에는 두 단어의 자모음이 총 5 개의 음소 중 4 개인 약 $80 \%$ (예: VCCVC 안경-안녕, CVCCV 달라-달려, CVCVC 바람-사람)가 공유되는 조건에 속하는 단어들로 구성된다. 각 조건 의 단어쌍은 10 개의 쌍으로 이루어져 있으며, 모든 단어들은 2 음절 의 길이로 통일하였다. 이는 영어에서의 알파벳과는 다르게 한국어 에서는 음성 분절 단위가 음소가 아닌 음절임을 언급한 관련 연구 에 근거한 것이다(Lee et al., 1995; Song et al., 2012). 전체 단어의 목
록은 Appendix 1에 제시하였다.

음운유사성 점수는 아동의 부모에게 보고받은 $\mathrm{CDI}$ 표현어휘 목 록을 점수화하여 P1-P3 각 조건에 속하는 단어쌍의 두 단어 모두 점수를 받은 경우 1 점을 부여하였다. 둘 중 하나의 단어만 표현어휘 목록에 존재하거나, 둘 다 표현어휘 목록에 존재하지 않은 경우는 0점을 부여받아 음운유사성 점수를 얻지 못하게 된다. 즉, 한 쌍의 단어 2개를 모두 표현어휘로 산출한 경우에만 음운유사성 점수를 부여하였다. 해당 점수는 최종적으로 획득 점수를 전체 항목수(10 개)로 나눈 다음 100 을 곱하여 \%점수로 산출되었다. 이 과정은 언 어병리학전공 석사과정학생 3 명, 박사과정학생 1 명이 목표 단어쌍 목록을 설정한 뒤, 각 아동의 $\mathrm{CDI}$ 검사지를 보며 각각의 항목을 점 수화해 전산 처리하였다.

\section{표현어휘력(expressive vocabulary)}

본 연구에서는 표준화된 부모보고 설문지인 '맥아더-베이츠 의 사소통발달 평가(K M-B CDI)'의 표현어휘 점수를 통해 표현어휘 력을 측정하였다. 본 연구에 참여한 모든 유아의 부모들에게 아동 이 표현하는 낱말을 표시하도록 하였다. 단, 아이가 뜻을 모르고 부 모의 말을 단순 모방하는 경우는 표현어휘력에서 제외하였다.

\section{연구절차}

음운유사도 검사는 아동의 K M-B CDI 검사지를 통해 언어병리 학전공 석사과정학생 3 인, 박사과정학생 1 인이 코딩한 후 검토하였 다. 추후 명확하지 않은 부분은 논의를 거쳐 의견을 하나로 수렴하 였으므로 각 항목별로 일치한 수의 비율을 측정한 분석자 간 신뢰 도 산출시 일치율은 $100 \%$ 였다.

\section{자료분석 및 결과처리}

연구 1 에서는 2 개의 시점(T1, T2)과 3 개의 음운유사도 유형 $(\mathrm{P} 1$, $\mathrm{P} 2, \mathrm{P} 3)$ 에 따른 음운유사도 양상을 확인하기 위해 반복측정분산 
분석(repeated measures ANOVA)을 실시하였으며, 3 가지 음운유 사도 유형 중 가장 표현어휘력을 잘 설명하는 유형을 확인하기 위 해 단계적 다중회귀분석(stepwise multiple regression)을 사용하였 다. 본 연구의 모든 통계 분석은 SPSS version 19 (SPSS Inc., Chicago, IL, USA)를 사용하였다.

\section{연구 2}

\section{연구대상}

연구 2에서는 만 $18-36$ 개월의 말늦은 아동 17 명(남 10 , 여 7)과, 연구 1 에 참여한 아동 18 명을 포함한 또래 일반아동 134 명(남 73 , 여 61$)$, 총 151 명의 아동이 참여하였다. TD 집단에 포함된 연구 1 의 18 명의 표헌어휘력 및 음운유사도 점수는 $\mathrm{T} 1$ 시점의 점수를 반영 한 것이다. 연구 1 과 동일하게 모든 유아들은 (1) 인지능력(DEP)이 -1 SD 이상으로 정상 범주에 속하고, (2) 시청각을 포함한 감각적인 어려움이 없고, (3) 부모로부터 현재 언어능력, 행동패턴, 활동 선호 도, 그리고 가족력에 대한 보고를 받아 이상이 없음을 확인하였다. 말늦은 아동은 (1) 표현어휘의 수가 50개 미만, (2) CDI 표현어휘 점 수가 해당 연령의 규준과 비교하여 $10 \%$ ile 미만인 경우 말늦은 아동 집단으로 분류하였다. 비구어 인지능력은 $\mathrm{LT}$ 집단은 112.24 점, $\mathrm{TD}$ 집단은 112.21점으로 통계적으로 유의한 차이가 없었으나 $(p>.05)$, 연령, 표현어휘 및 문법 점수는 유의한 차이가 있었다. 특히 LT 집단 에서 표현어휘 점수는 39.00 점으로 TD 집단의 365.64점과 유의한 차이가 있었으며, $\mathrm{LT}$ 집단에서 문법 점수는 7.88점으로 $\mathrm{TD}$ 집단의 34.89 점과 유의한 차이가 있었다 $(p<.01)$. 세부적인 내용은 Table 1 에 제시하였다.

\section{연구자료}

단어의 음운유사성(phonological similarity)

연구 1 과 동일하게 설문지인 '맥아더-베이츠 의사소통발달 평가 (K M-B CDI)'의 18-36개월 대상의 유아용 설문지를 활용하였으며, 동일한 제작 과정 및 점수 산출 체계, 그리고 타당도 산출 과정을 거쳤다.

표현어휘력(expressive vocabulary)

연구 1과 동일하게 표준화된 부모보고 설문지인 '맥아더-베이츠 의사소통발달 평가(K M-B CDI)'의 표현어휘 점수를 통해 표현어 휘력을 측정하였다.

\section{연구절차}

연구 1 과 동일한 절차를 거쳤다.

\section{자료분석 및 결과처리}

연구 2에서는 앞서 살펴본 연구대상의 특성에서 LT와 TD집단 간 연령에서 통계적으로 유의한 차이가 나타난 것을 고려해 연령을 통제한 집단 간 음운유사도 양상을 확인하기 위해 공변량분석 (ANCOVA)을 실시하였으며, 각 집단의 표현어휘력을 가장 잘 설명 하는 음운유사도 유형을 확인하기 위해 단계적 다중회귀분석을 사용하였다. 본 연구의 모든 통계 분석은 SPSS version 19 (SPSS Inc., Chicago, IL, USA)를 사용하였다.

\section{연구결과}

\section{연구 1}

시간 차에 따른 음운유사도 양상 차이

만 18-36개월의 동일한 아동 18 명에 대해 약 8개월의 간격을 두고 음운유사도 양상에 어떤 변화가 있었는지 확인하였다. 그 결과, $\mathrm{T} 1$ 과 T2 시점 간 음운유사도 양상에 통계적으로 유의한 차이가 있었 다 $\left(F_{(1,17)}=28.64, p<.001\right)$. 즉, $\mathrm{T} 1$ 에서 유아들은 12.96 점을 받았는 데, T2에서는 48.89점을 받아 유의한 점수의 증가를 보였다. 음운유 사도 3 가지 유형에 따른 차이 또한 통계적으로 유의하였다 $\left(F_{(2,34)}=\right.$ $5.02, p<.05)$. 즉, $\mathrm{P} 1$ 의 평균은 33.61점, $\mathrm{P} 2$ 는 32.78점, $\mathrm{P} 3$ 은 26.39점이 었다. 이에 따라 세부적으로 어떤 조건 간 차이가 유의했는지 확인 한 결과, P1과 P3 간 차이가 유의하였다 $(p=.05)$. 또한, 시점 및 음운 유사도 간 이차상호작용이 유의한 것으로 나타났다 $\left(F_{(2,34)}=6.91\right.$, $p<.01)$. 이에 사후분석을 실시한 결과, $\mathrm{T} 1$ 시점에서는 $\mathrm{P} 1-\mathrm{P} 2$ 간 차 이가 유의했지만 $\left(t_{(17)}=3.289, p<.01\right), \mathrm{T} 2$ 시점에서는 P1-P2 간 차이 $\left(t_{177}=-2.374, p<.05\right)$ 뿐만 아니라 $\mathrm{P} 2$ 와 $\mathrm{P} 3$ 의 차이도 유의하게 나타 났다 $\left(t_{(17)}=2.934, p<.01\right)$. 특히, $\mathrm{T} 1$ 시점에서는 $\mathrm{P} 1$ 의 점수가 유의하 게 가장 높았으나, $\mathrm{T} 2$ 시점에서는 $\mathrm{P} 2$ 점수가 유의하게 가장 높은 것 으로 나타나차이를 보였다. 이에 따른 결과를 Table 2에 제시하였다.

서로 다른 시점에서의 표현어휘력에 대한 음운유사도의 설명력 $\mathrm{T} 1$ 시점에서의 음운유사도 점수가 $\mathrm{T} 1$ 과 $\mathrm{T} 2$ 시점의 표현어휘력

Table 2. Descriptive statistics of phonological similarity scores (T1-T2)

\begin{tabular}{lccc}
\hline & $\mathrm{T} 1(\mathrm{~N}=18)$ & $\mathrm{T} 2(\mathrm{~N}=18)$ & Total \\
\hline P1 (max score $=100)$ & $18.33(7.15)$ & $48.89(7.41)$ & $33.61(6.39)$ \\
P2 (max score $=100)$ & $10.56(5.91)$ & $55.00(8.14)$ & $32.78(6.01)$ \\
P3 (max score $=100)$ & $10.00(5.60)$ & $42.78(7.75)$ & $26.39(5.87)$ \\
Total & $12.96(6.00)$ & $48.89(7.53)$ & \\
\hline
\end{tabular}

Values are presented as mean (SE). $\mathrm{T} 1$ = time1; $\mathrm{T} 2$ = time2 . 
을 유의하게 설명해 주는지, 얼마나 설명해 주는지 살펴보기 위하 여 3가지 유형의 음운유사도 점수인 P1, P2, P3를 독립변수로 하여 단계적 중다회귀분석(stepwise multiple regression)을 실시하였다. 독립변수 간의 다중공선성을 진단하기 위한 VIF는 모두 1.528로, 1 에 근접하여 독립변수 간의 상관이 문제가 될 정도로 높지 않았다.

그 결과, $\mathrm{T} 1$ 시점에서 표현어휘력을 가장 잘 설명해 주는 $\mathrm{T} 1$ 시점 의 음운유사도 유형은 $\mathrm{P} 1$ 인 것으로 나타났다. 즉, $\mathrm{T} 1$ 시점의 표현어 휘력에 대해 $\mathrm{P} 1$ 이 약 $93.1 \%$ 유의하게 설명해 주는 것으로 나타났다 $\left(F_{(1,16)}=215.75, \mathrm{R}^{2}=.931, p<.001\right)$. 또한, $\mathrm{T} 2$ 시점에서 표현어휘력을 가장 잘 설명해주는 $\mathrm{T} 1$ 시점의 음운유사도 유형 역시 $\mathrm{P} 1$ 인 것으로 나타났다. 즉, $\mathrm{T} 2$ 시점의 표현 어휘력에 대해 $\mathrm{T} 1$ 시점의 $\mathrm{P} 1$ 이 약 $25.7 \%$ 유의하게 설명해주는 것으로 나타났다 $\left(F_{(1,16)}=5.525, \mathrm{R}^{2}=.257, p<\right.$ .05). 이에 대한 결과를 Figure 1에 제시하였다.

\section{연구 2}

음운유사도 양상에서의 집단(말늦은 아동, 일반아동) 간 차이

만 18-36개월의 말늦은 아동 17 명, 또래 일반아동 134 명에 대해 음운유사도 양상에 집단 간 차이가 존재하는지 확인하였다. 집단 간 연령의 차이가 통계적으로 존재하여 연령을 통제한 공변량분석 (ANCOVA)을 실시하였다. 그 결과, 말늦은 아동과 또래 일반아동 간 음운유사도 점수에 통계적으로 유의한 차이가 있었다 $\left(F_{(1,148)}=\right.$ $21.62, p<.001)$. 즉, 말늦은 아동은 11.49 점을 받은 반면 또래 일반 아동은 44.19점을 받았다. 그러나, 음운유사도 3가지 유형에 따른 차이는 통계적으로 유의하지 않은 것으로 나타났으며 $(p>.05)$, 집 단 및 음운유사도 간 이차상호작용도 유의하지 않은 것으로 나타 났다( $p>.05)$. 이에 따른 결과를 Table 3 에 제시하였다.

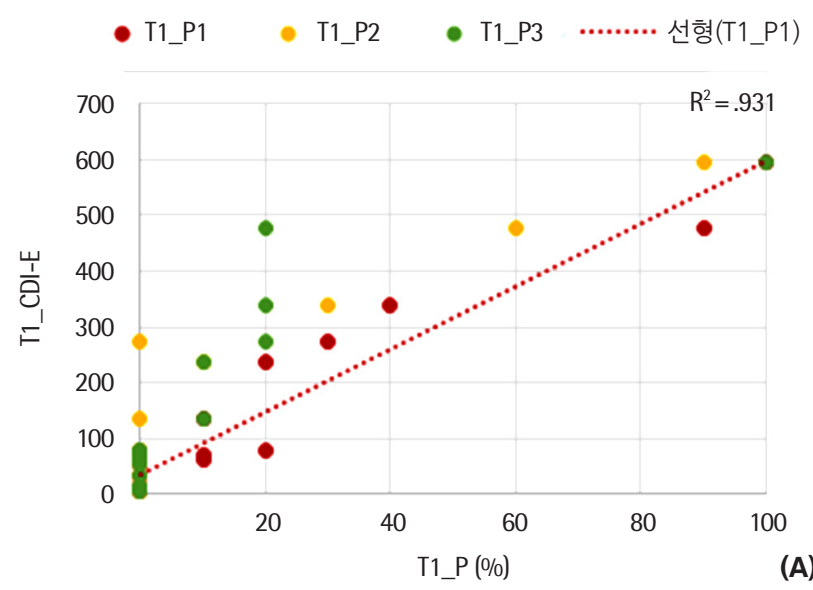

각 집단의 표현어휘력에 대한 음운유사도의 설명력

말늦은 아동 집단 및 또래 일반아동의 음운유사도 유형 중 표현 어휘력을 유의하게 설명해 주는 요인이 있는지, 있다면 얼마나 설명 력을 지니고 있는지 살펴보기 위하여 3 가지 유형의 음운유사도 점 수인 P1, P2, P3를 독립변수로, 표현어휘력을 종속변수로 하여 단계 적 중다회귀분석(stepwise multiple regression)을 실시하였다. 독립 변수 간의 다중공선성을 진단하기 위한 VIF는 $1.815,1.325$ 로, 1 에 근접하여 독립변수 간의 상관이 문제가 될 정도로 높지 않았다.

그 결과, 말늦은 아동 집단의 표현어휘력을 가장 잘 설명해 주는 음운유사도 유형은 $\mathrm{P} 1$ 인 것으로 나타났다. 즉, 말늦은 아동 집단의 표현어휘력에 대해 $\mathrm{P} 1$ 이 약 $35.5 \%$ 유의하게 설명해 주는 것으로 나 타났다 $\left(F_{(1,15)}=8.252, r^{2}=.355, p<.05\right)$. 이에 대한 결과를 Table 4 에 제시하였다.

또래 일반아동 집단의 표현어휘력을 유의하게 설명해 주는 음운 유사도 유형은 모든 유형으로 나타났으며 P1, P3, P2 순으로 나타났 다. 즉, 말늦은 아동과 동일하게 $\mathrm{P} 1$ 의 설명력이 가장 높게 나타났고 약 $91.1 \%$ 유의하게 설명해 주는 것으로 나타났다 $\left(F_{(1,132)}=1,357.63\right.$,

Table 3. Differences between groups in phonological similarity scores (TD-LT)

\begin{tabular}{lccc}
\hline & TD (N=134) & LT (N=17) & Total \\
\hline P1 (max score=100) & $46.97(2.30)$ & $12.71(6.56)$ & $29.84(3.46)$ \\
P2 (max score = 100) & $43.51(2.53)$ & $11.17(7.21)$ & $27.34(3.81)$ \\
P3 (max score=100) & $42.09(2.41)$ & $10.61(6.88)$ & $26.35(3.63)$ \\
Total & $44.19(2.32)$ & $11.49(6.61)$ & \\
F & $8.351^{* *}$ & 1.895 & \\
\hline
\end{tabular}

Values are presented as mean (SE).

$\mathrm{TD}=$ typically developing children; $\mathrm{LT}=$ late talkers.

${ }^{* *} p<.01$.

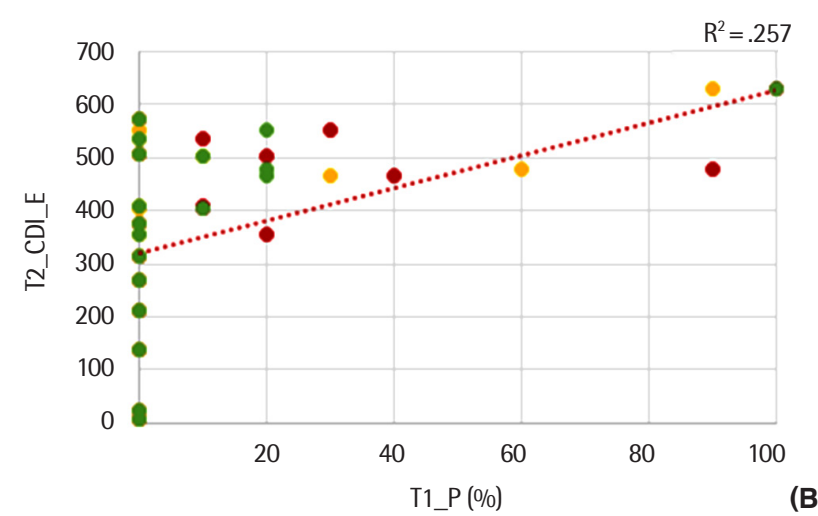

(B)

Figure 1. Predictor of overall expressive vocabulary. (A) Best explanatory power of expressive vocabulary at T1 (IV: T1_P1 / DV: T1_CDI_E). (B) Best explanatory power of expressive vocabulary at T2 (IV: T1_P1 / DV: T2_CDI_E). 
Table 4. Predictors of expressive vocabulary in LT group

\begin{tabular}{|c|c|c|c|c|c|c|}
\hline \multirow{2}{*}{\multicolumn{2}{|c|}{ Predictor }} & \multicolumn{2}{|c|}{$\begin{array}{l}\text { Non-standardized } \\
\text { coefficients }\end{array}$} & \multirow{2}{*}{$\begin{array}{l}\text { Standard- } \\
\text { ized coef- } \\
\text { ficients }\end{array}$} & \multirow[t]{2}{*}{$\Delta \mathrm{R}^{2}$} & \multirow[t]{2}{*}{$p$-value } \\
\hline & & B & SE & & & \\
\hline Step 1 & P1 & 5.480 & 1.908 & .596 & .355 & .012 \\
\hline
\end{tabular}

$\mathrm{LT}=$ late talkers.

$\mathrm{R}^{2}=.911, p<.001$ ). 또한, $\mathrm{P} 1$ 에 $\mathrm{P} 3$ 를 추가 입력하였을 때 약 $2.5 \%$ 설명 력이 증가하여 총 설명력은 $93.6 \%\left(F_{(2,131)}=954.51, \mathrm{R}^{2}=.936, p<.001\right)$. 또한, P1과 P3에 P2를 추가 입력하였을 때 약 $0.3 \%$ 설명력이 증가하 여 총 설명력은 $93.9 \%$ 인 것으로 나타났다 $\left(F_{(3,130)}=662.58, \mathrm{R}^{2}=.939\right.$, $p<.001)$. 이에 대한 결과를 Table 5에 제시하였다.

\section{논의 및 결론}

\section{연구 1}

본 연구 1 에서는 만 18-36개월 유아 18 명의 추적연구를 통해 두 시점에 따른 음운유사도 양상의 변화를 살펴보고, 앞 시점인 $\mathrm{T} 1$ 시 점의 음운유사도 점수 중 어떤 유형이 $\mathrm{T} 1, \mathrm{~T} 2$ 각각의 표현어휘력을 가장 잘 설명해줄 수 있는지 살펴보았다.

첫째, 연구 1 에서 유아들은 시간의 흐름에 따라 음운유사도 점 수에 유의한 증가 양상을 보였다. 일반적으로 만 18-36개월에 속하 는 유아들은 단어 폭발기를 거쳐 급격한 어휘의 증가를 겪게 되며, 산발적으로 습득되고 저장되어 왔던 어휘들이 공유되는 특성에 따라 유사성을 중심으로 함께 묶이거나 세부 특성에 따라 변별된 다. 즉, 어휘 크기의 증가에 따라 음운적으로 유사한 서로 다른 낱 말들의 세부적 특성을 구별할 수 있게 되고, 이 능력이 또한 더 많 은 어휘를 학습할 수 있게 하는 것이다(Werker et al., 2002). 또한 음운유사도 양상에 따른 3 가지 유형 간 차이 또한 유의하였는데, 이는 음운적으로 유사한 특성 가운데에서도 만 3 세 이전의 유아의 경우 상대적으로 많은 음소들을 공유하는 P3 조건에 비해 적은 음 소들을 공유하는 P1 조건에서 더 높은 점수를 얻을 수 있는 것으로 보인다. Vitevitch와 Luce (2016) 역시 음운적으로 유사한 단어들은 더 느리게, 그리고 덜 정확하게 처리됨을 발견하였으며, Luce와 $\mathrm{Pi}-$ soni (1998) 역시 구어로 CVC 구조의 단어를 제시하였을 때 유사성 이 높은 단어는 낮은 단어에 비해 덜 정확하게 식별되므로 서로 각 기 다른 단어로 인식하는 데에 방해 요소로 간주될 수 있음을 시사 하여 이러한 선행연구의 결과를 뒷받침해 준다. 즉, 3 세 무렵의 아동 들이 유사한 음운 특성을 지닌 서로 다른 단어들을 구분해낼 수 있 다고 하더라도, 3 세 이전의 아주 어린 연령의 아동들의 어휘집(lexicon)은 음운유사성이 낮은 단어로 구성되어 있다(Barton, 1978;
Table 5. Predictors of expressive vocabulary in TD group

\begin{tabular}{|c|c|c|c|c|c|c|}
\hline & \multirow{2}{*}{ Predictor } & \multicolumn{2}{|c|}{$\begin{array}{l}\text { Non-standardized } \\
\text { coefficients }\end{array}$} & \multirow{2}{*}{$\begin{array}{l}\text { Standard- } \\
\text { ized coef- } \\
\text { ficients }\end{array}$} & \multirow[t]{2}{*}{$\Delta \mathrm{R}^{2}$} & \multirow[t]{2}{*}{$p$-value } \\
\hline & & B & SE & & & \\
\hline Step 1 & $\mathrm{P} 1$ & 5.335 & .145 & .955 & .911 & .000 \\
\hline \multirow[t]{2}{*}{ Step 2} & P1 & 3.442 & .296 & .616 & .936 & .000 \\
\hline & P3 & 2.037 & .289 & .373 & & .000 \\
\hline \multirow[t]{3}{*}{ Step 3} & P1 & 2.984 & .345 & .534 & .939 & .000 \\
\hline & P3 & 1.589 & .337 & .291 & & .000 \\
\hline & P2 & .878 & .359 & .169 & & .016 \\
\hline
\end{tabular}

$\mathrm{TD}=$ typically developing children .

Dollaghan, 1994). 아동의 연령이 어릴수록 이러한 경향은 두드러 겼다. Hollich, Jusczyk와 Luce (2002)의 연구에서도 음운유사성에 따른 비단어 습득 여부를 확인한 결과, 유사성이 낮은 조건에서는 비단어를 습득하였지만, 유사성이 높은 단어에서는 도리어 낮은 수행을 보여주었다. 이를 통해 3 세 이하의 아동의 경우 음운유사성 이 낮은 단어의 습득이 상대적으로 수월함을 확인할 수 있다.

그에 덧붙여서 본 연구에서는 $\mathrm{T} 1$ 시점에 비해 $\mathrm{T} 2$ 시점에서 $\mathrm{P} 1$ 보 다 상대적으로 더 높은 음운유사성을 보이는 P2 조건에서 높은 점 수를 받는 것으로 나타났는데, 이는 아동이 $\mathrm{T} 1$ 시점에서 약 8 개월 이 지난 T2 시점에서 더욱 음운적으로 유사한 조건의 두 단어들을 서로 다른 것으로 인식하고 또 표현할 수 있는 능력이 증가하였음 을 시사한다. 유아들의 초기 어휘집에는 비슷한 소리를 지닌 단어 가 성인에 비해 적지만, 연령이 증가함에 따라 점점 더 많은 단어를 습득하게 되면서 비슷한 소리를 지닌 단어들도 증가하게 된다(Munson, Swenson, \& Manthei, 2005). Fowler (1991)의 연구에 의하면 음운 표상은 시간이 지날수록 전체에서 점차 부분으로 조직화된다 고 하였으며, Zieglerd와 Goswami (2005)는 아동기의 음운 표상이 큰 단위에서 작은 단위로 발달된다고 설명하였다.

둘째, 연구 1 에서 $\mathrm{T} 1, \mathrm{~T} 2$ 시점 각각의 표현어휘력을 가장 잘 설명 해 주는 $\mathrm{T} 1$ 시점의 음운유사도 유형은 일관적으로 $\mathrm{P} 1$ 인 것으로 나 타났다. 즉, $18-36$ 개월 사이 유아들의 표현어휘는 급격하게 증가함 에도 불구하고, 어휘의 음운유사도는 상대적으로 가장 낮은 조건인 $\mathrm{P} 1$ 이 표현어휘력 점수에 크게 기여하는 것으로 나타난다. 적어도 만 3 세까지의 어린 연령대에서는, 공유하는 음소가 더 적을 때 각 단어 가 더 쉽게 구별되기 때문에 어휘를 산출할 때는 음운유사도가 상 대적으로 낮은 조건이 더욱 기여도가 높을 수 있음을 보여준다.

\section{연구 2}

연구 2에서는 만 18-36개월의 말늦은 아동 및 또래 일반아동 간 음운유사도 양상에 어떠한 차이를 보이는지, 각 집단의 표현어휘력 
을 가장 잘 설명해 주는 음운유사도 유형은 무엇인지 살펴보고자 하였다.

첫째, 연구 2에서 LT와 TD 집단 간 음운유사도에서 유의한 차이 가 있었다. 세부적인 음운유사도 유형에 관계없이, 단어의 음운유 사성이 존재하는 단어들을 서로 다른 단어로 표현하는 능력에서 말늦은 집단은 또래 일반아동 집단에 비해 부족함을 나타낸 것이 다. 또한, $\mathrm{TD}$ 집단에서는 음운유사도 유형에 따른 점수 차이가 유 의하였으나, LT 집단에서는 음운유사도 유형에 따른 점수 차이가 유의하지 않았다. 즉, $\mathrm{LT}$ 집단은 또래 TD 집단에 비해 세부적인 음 운유사도 유형에 관계없이 일관되게 낮은 점수를 보였으나, $\mathrm{TD}$ 아 동 집단은 음운유사도가 높은 $\mathrm{T} 2$, T3에 비해 음운유사도가 낮은 $\mathrm{T} 1$ 에 속했을 때 더 유의하게 높은 점수를 얻은 것이다. Paul과 Jennings (1992)는 18-34개월 유아를 대상으로 한 연구에서, 표현어휘 발달지연 아동의 경우 음운구조의 복잡성, 서로 다른 자음의 수, 발 화 내 정확하게 산출된 자음 비율에서 일반아동에 비해 부족한 수 행을 보였다고 보고하였다. 이러한 결과는 표현어휘발달지연 아동 이 음운적으로 일반아동에 비해 덜 발달되었음을 보여주며, 말늦 은 아동이 느린 음운처리능력이 이들의 느린 표현어휘발달의 주된 원인이 될 수 있음을 시사한다. Fletcher 등(2004)의 연구에서는 $\mathrm{CDI}$ 검사를 통해 말늦은 아동을 세 집단으로 나누어, 음운과 어휘 발달의 관계를 연구하였다. 그 결과, 표현하는 어휘가 많은 집단일 수록 다양한 자음 목록을 보여, 어휘와 음운이 서로 관계가 있음을 보고하였다. 국내에서는 Choi 등(2014)의 연구에서 2세 아동의 자 발화를 수집하여 어휘능력과 음운능력의 상관관계를 연구하였다. 그 결과, 어휘능력을 나타내는 서로다른 낱말수(number of different word, NDW)와 음운능력을 나타내는 단어단위정확률(proportion of whole-word correctness, PWC), 평균음운길이(phonological mean length of utterance, PMLU), 단어단위근접률(proportion of whole-word proximity, PWP), 자음정확도(percentage of consonants corret, $\mathrm{PCC}$ ) 간에 정적 상관을 보였으며, NDW와 음운변동 빈도는 부적 상관을 보였다. 이와 같은 결과는 다른 언어 권의 아동들처럼 한국어권의 아동들에게도 음운능력과 어휘능력 간 상관이 나타나며, 음운능력에 제한이 있는 아동은 어휘능력에 도 어려움이 있을수 있다는 것을 암시한다.

둘째, 연구 2에서 LT 집단의 표현어휘력을 가장 잘 설명해 주는 음운유사도 유형은 상대적으로 낮은 유사도의 특징을 갖는 $\mathrm{P} 1$ 인 것으로 나타났으며, TD 집단의 표현어휘력을 가장 잘 설명해 주는 음운유사도 유형은 LT와 동일하게 $\mathrm{P} 1$ 인 것으로 나타났으나 P3, P2 도 모두 유의한 설명력을 지니는 것으로 나타난다. 이는 LT 집단의 표현어휘력에 상대적으로 가장 낮은 음운유사도 조건이었던 P1 만
이 기여하는 반면, TD 집단의 표현어휘력에는 모든 유형의 음운유 사성 조건이 다각적으로 기여하는 것으로 분석된다. Maillart, Schelstraete와 Hupet (2004)의 연구에서 SLI 아동과 일반아동을 대상으 로 기존 단어에 일부 음소를 추가하거나 삭제하여 유사 비단어를 만든 후 청각적 어휘변별 과제를 수행하도록 하였다. 그 결과, SLI 아동은 일반아동에 비해 부족한 수행능력을 보였는데, 이는 SLI 아동이 일반아동에 비해 음운표상 능력이 부족하며, 일반아동은 SLI 아동보다 상대적으로 더 견고한 음운표상 능력을 갖추고 있음 을 보여준다. LT 아동 역시 새로운 언어를 습득할 때 일반아동보다 오랜 시간을 필요로 하며, 특히 음운작업기억의 결함이 단어습득 을 방해하는 중요한 요인으로 꼽힌다고 하였다(Alt \& Plante, 2006). 즉, 음운작업기억의 결함은 음운습득의 어려움으로 이어져 음운 과 단어의 뜻을 연결시키는 데 어려움을 보일 수 있다(Alt \& Plante, 2006; Dollaghan, 1987; Ellis Weismer \& Evans, 2002; Gray, 2004).

결론적으로 본 연구에서는 18-36개월 사이의 유아들의 표현어 휘는 급격하게 증가함에도 불구하고, 어휘의 음운유사도는 상대적 으로 가장 낮은 조건이 P1이 일관적으로 표현어휘력에 크게 기여하 는 것으로 나타난다. 적어도 만 3 세까지는 공유하는 음소가 더 적 을 때 각 단어가 더 쉽게 구별되기 때문에 어휘를 산출할 때는 음운 유사도가 낮은 조건이 더욱 기여도가 높을 수 있음을 시사한다. 또 한, 상대적으로 더 많은 음소들을 공유하는 P2, P3이 TD 집단에서 표현어휘력을 유의하게 설명해 줄 수 있었던 것은 음운네트워크가 긴밀할수록 표현어휘력에도 더 많은 기여를 할 수 있었기 때문인 것 으로 보인다. 반면, 단어 간 공유음소수가 상대적으로 적은 $\mathrm{P} 1$ 은 $\mathrm{LT}$ 집단에서 표현어휘력을 설명하는 유일한 예측요인인 것으로 나 타났는데, 이는 LT 집단의 유아들이 상대적으로 음운유사도가 낮 은 조건이 표현어휘를 습득하기에 더욱 적합한 조건일 것으로 추론 해볼 수 있다. 이 결과는 만 36 개월 이전까지 유효한 것으로 보인다.

본 연구의 제한점으로는 다음과 같다. 첫째, K M-B CDI 내 641 개의 단어 중 2 음절에 해당하는 단어 총 60 개만 사용하였다는 점 이다. 통제된 길이 내에서의 단어들의 음운유사성 양상을 살펴보 고자 음절수를 제한하고 조건에 맞는 단어들로 제한하였으나 표본 단어가 많아질수록 더 정확한 결과를 낼 수 있기 때문에, K M-B $\mathrm{CDI}$ 내외의 더 많은 단어들이 분석에 포함된다면 더욱 풍부한 논 의가 이루어질 수 있을 것이다. 나아가 후속연구에서는 음운유사 성 외에도 단어가 지닌 다른 특성(예: 품사 혹은 자음-모음 순서 및 구조 등)도 자세히 살펴본다면, 36 개월 이전 아동의 단어습득 특성 을 밝힐 수 있는 유용한 지표가 될 수 있을 것이다. 둘째, 본 연구의 단어목록으로 사용된 단어들은 모두 18-36개월 유아용 K M-B $\mathrm{CDI}$ 에 수록되어 본 연구대상의 연령과 일치하여 단어 및 난이도에 
는 영향이 크지 않을 것으로 보이지만, 후속연구에서는 더욱 정교 하게 통제할 수 있을 것이다. 셋째, 연구 2에서 TD 집단에 비해 LT 집단 아동의 수가 현저히 적었으므로 회귀분석의 결과해석 시 이 를 고려해야한다.

\section{REFERENCES}

Alt, M., \& Plante, E. (2006). Factors that influence lexical and semantic fast mapping of young children with specific language impairment. Journal of Speech, Language, and Hearing Research, 49(5), 941-954.

Barton, D. (1978). The discrimination of minimally-different pairs of real words by children aged 2;3 to 2;11. In: N. Waterson \& C. Snow (Eds.), The development of communication (pp. 255-261). New York, NY: Wiley.

Benasich, A. A., \& Tallal, P. (2002). Infant discrimination of rapid auditory cues predicts later language impairment. Behavioural Brain Research, 136(1), 31-49.

Carlson, M. T., Sonderegger, M., \& Bane, M. (2014). How children explore the phonological network in child-directed speech: a survival analysis of children's first word productions. Journal of Memory and Language, 75, 159-180.

Choi, M. S., Kim, S. J., \& Kim, H. S. (2014). Lexical and phonology development in 2-year-old Korean children. Korean Journal of Early Childhood Special Education, 14(1), 133-152.

Dollaghan, C. A. (1987). Fast mapping in normal and language-impaired children. Journal of Speech and Hearing Disorders, 52(3), 218-222.

Dollaghan, C. A. (1994). Children's phonological neighbourhoods: half empty or half full? Journal of Child Language, 21(2), 257-271.

Ellis Weismer, S., \& Evans, J. L. (2002). The role of processing limitations in early identification of specific language impairment. Topics in Language Disorders, 22(3), 15-29.

Fenson, L., Dale, P. S., Reznick, J. S., Bates, E., Thal, D. J., Pethick, S. J., ... \& Stiles, J. (1994). Variability in early communicative development. Monographs of the Society for Research in Child Development, 59(5), i-185.

Fletcher, P., Chan, C. W. Y., Wong, P. T. T., Stokes, S., Tardif, T., \& Leung, S. C. S. (2004). The interface between phonetic and lexical abilities in early Cantonese language development. Clinical Linguistics \& Phonetics, 18(6-8), 535-545.

Fowler, A. E. (1991). How early phonological development might set the stage for phoneme awareness. In: S. A. Brady \& D. P. Shankweiler (Eds.), Phonological processes in literacy: a tribute to Isabelle Y. Liberman (pp. 97-117).
Mahwah, NJ: Lawrence Erlbaum Associates.

Gahl, S., \& Strand, J. F. (2016). Many neighborhoods: Phonological and perceptual neighborhood density in lexical production and perception. Journal of Memory and Language, 89, 162-178.

Gathercole, S. E., \& Baddeley, A. D. (1990). The role of phonological memory in vocabulary acquisition: a study of young children learning new names. British Journal of Psychology, 81(4), 439-454.

Gray, S. (2004). Word learning by preschoolers with specific language impairment. Journal of Speech, Language, and Hearing Research, 47(5), 11171132.

Guttorm, T. K., Leppänen, P. H., Poikkeus, A. M., Eklund, K. M., Lyytinen, P., \& Lyytinen, H. (2005). Brain event-related potentials (ERPs) measured at birth predict later language development in children with and without familial risk for dyslexia. Cortex, 41(3), 291-303.

Ha, S., \& Pi, M. (2018). Phonological characteristics of early lexicon in Korean-acquiring children. Communication Sciences \& Disorders, 23(4), 829844 .

Hawa, V. V., \& Spanoudis, G. (2014). Toddlers with delayed expressive language: an overview of the characteristics, risk factors and language outcomes. Research in Developmental Disabilities, 35(2), 400-407.

Hollich, G., Jusczyk, P. W., \& Luce, P. A. (2002). Lexical neighborhood effects in 17-month-old word learning. Proceedings of the 26th Annual Boston University Conference on Language Development, Boston, MA, 314-323.

Jang, H. S., Seo, S. J., \& Ha, J. Y. (2011). Developmental assessment for the early intervention program planning. Seoul: Hakjisa.

Jarvis, L. H., Merriman, W. E., Barnett, M., Hanba, J., \& Van Haitsma, K. S. (2004). Input that contradicts young children's strategy for mapping novel words affects their phonological and semantic interpretation of other novel words. Journal of Speech, Language, and Hearing Research, 47(2), 392-406.

Joanisse, M. F., \& Seidenberg, M. S. (2003). Phonology and syntax in specific language impairment: evidence from a connectionist model. Brain and Language, 86(1), 40-56.

Kim, S. S. (2005). The role of phonological similarity of target words on fastmapping strategy of children with SLI. Korean Journal of Communication \& Disorders, 10(1), 25-42.

Kim, Y. T. (2014). Diagnosis and treatment of childhood language disorders. Seoul: Hakjisa.

Kuhl, P. K., Conboy, B. T., Coffey-Corina, S., Padden, D., Rivera-Gaxiola, M., \& Nelson, T. (2007). Phonetic learning as a pathway to language: new data and native language magnet theory expanded (NLM-e). Philosophical Trans- 
actions of the Royal Society B: Biological Sciences, 363(1493), 979-1000.

Lee, K., Lee, H., \& Park, H. (1995). A psychological study on Korean phonological structure: the syllable's role in speech segmentation. The Journal of the Humanities, 17(1), 429-453.

Luce, P. A., \& Pisoni, D. B. (1998). Recognizing spoken words: the neighborhood activation model. Ear and Hearing, 19(1), 1-36.

Maillart, C., Schelstraete, M. A., \& Hupet, M. (2004). Phonological representations in children with SLI. Journal of Speech, Language, and Hearing Research, 47(1), 187-198.

Munson, B., Swenson, C. L., \& Manthei, S. C. (2005). Lexical and phonological organization in children. Journal of Speech, Language, and Hearing Research, 48(1), 108-124.

Pae, S., \& Kwak, K. C. (2011). Korean MacArthur-Bates Communicative Development Inventories (KM-B CDI). Seoul: Mindpress.

Paul, R. (1996). Clinical implications of the natural history of slow expressive language development. American Journal of Speech-Language Pathology, 5(2), 5-21.

Paul, R., \& Jennings, P. (1992). Phonological behavior in toddlers with slow expressive language development. Journal of Speech, Language, and Hearing Research, 35(1), 99-107.

Rescorla, L. (2002). Language and reading outcomes to age 9 in late-talking toddlers. Journal of Speech, Language, and Hearing Research, 45(2), 360371.

Rescorla, L., \& Alley, A. (2001). Validation of the language development survey (LDS). Journal of Speech, Language, and Hearing Research, 44(2), 434445.

Rivera-Gaxiola, M., Klarman, L., Garcia-Sierra, A., \& Kuhl, P. K. (2005). Neural patterns to speech and vocabulary growth in American infants. NeuroReport, 16(5), 495-498.
Song, J. Y., Nam, K. C., \& Koo, M. M. (2012). The effect of word frequency and neighborhood density on spoken word segmentation in Korean. Phonetics and Speech Sciences, 4(2), 3-20.

Stoel-Gammon, C. (2011). Relationships between lexical and phonological development in young children. Journal of Child Language, 38(1), 1-34.

Stokes, S. F. (2010). Neighborhood density and word frequency predict vocabulary size in toddlers. Journal of Speech, Language, and Hearing Research, 53(3), 670-683.

Stokes, S. F., Bleses, D., Basbøll, H., \& Lambertsen, C. (2012). Statistical learning in emerging lexicons: The case of Danish. Journal of Speech, Language, and Hearing Research, 55(5), 1265-1273.

Storkel, H. L. (2004). Do children acquire dense neighborhoods? An investigation of similarity neighborhoods in lexical acquisition. Applied Psycholinguistics, 25(2), 201-221.

Storkel, H. L. (2009). Developmental differences in the effects of phonologi$\mathrm{cal}$, lexical and semantic variables on word learning by infants. Journal of Child Language, 36(2), 291-321.

Storkel, H. L., Armbrüster, J., \& Hogan, T. P. (2006). Differentiating phonotactic probability and neighborhood density in adult word learning. Journal of Speech, Language, and Hearing Research, 49(6), 1175-1192.

Vitevitch, M. S., \& Luce, P. A. (2016). Phonological neighborhood effects in spoken word perception and production. Annual Review of Linguistics, 2, 75-94.

Werker, J. F., Fennell, C. T., Corcoran, K. M., \& Stager, C. L. (2002). Infants' ability to learn phonetically similar words: effects of age and vocabulary size. Infancy, 3(1), 1-30.

Ziegler, J. C., \& Goswami, U. (2005). Reading acquisition, developmental dyslexia, and skilled reading across languages: a psycholinguistic grain size theory. Psychological Bulletin, 131(1), 3-29. 
Appendix 1. List of word pairs in each phonological similarity types

\begin{tabular}{|c|c|c|c|c|c|c|c|c|c|c|c|c|c|c|c|c|c|c|c|c|c|c|c|c|c|c|c|c|c|}
\hline \multicolumn{14}{|c|}{ P1 (66\%) } & \multicolumn{16}{|c|}{ P2 $(75 \%)$} \\
\hline $\begin{array}{l}\text { 가위 } \\
\text { kawi] }\end{array}$ & $\neg$ & r & Tl & $\begin{array}{c}\text { 끼워 } \\
\text { [K'iwn] }\end{array}$ & 77 & 1 & TA [r & $\begin{array}{c}\text { 매워 } \\
{[\mathrm{m \varepsilon w} \text { ] }}\end{array}$ & ㅁ & $H$ & TA & $\begin{array}{c}\text { 아가 } \\
\text { [aga] }\end{array}$ & $\vdash \neg$ & $\begin{array}{c}\text { 고쳐 } \\
{\left[\text { kots }^{\mathrm{h}} \mathrm{N}\right]}\end{array}$ & $\neg$ & $\perp$ & 大 & 牛 & $\begin{array}{c}\text { 물어 } \\
\text { [mur }]\end{array}$ & ㅁ. & $T$ ᄅ & 1 & $\begin{array}{c}\text { 다리 } \\
\text { [tari] }\end{array}$ & ᄃ & & 21 & {$\left[\begin{array}{c}\text { 하나 } \\
\text { [hana] }\end{array}\right.$} & ᄒ ト ᄂ & \\
\hline $\begin{array}{l}\text { 거위 } \\
\text { kn^wi] }\end{array}$ & $\neg$ & -1 & $T$ & $\begin{array}{c}\text { 미워 } \\
\text { [miwn] }\end{array}$ & $\square$ & 1 & 겨 [ & $\begin{array}{c}\text { 태워 } \\
{\left[\mathrm{t}^{\mathrm{n}} \mathrm{WW} \mathrm{N}\right]}\end{array}$ & $E$ & H & TA & $\begin{array}{c}\text { 악어 } \\
\text { [ag^] }\end{array}$ & ト ᄀ & $\left.\begin{array}{c}\text { 고추 } \\
{\left[\mathrm{kots}^{n} \mathrm{u}\right]}\end{array}\right]$ & $\neg$ & $\perp$ & 太 T & $T$ & $\begin{array}{c}\text { 밀어 } \\
\text { [mirs] }\end{array}$ & ㅁ & 1 e & 1 & $\begin{array}{l}\text { 다시 } \\
\text { [taci] }\end{array}$ & ᄃ & tᄉ & ᄉ 1 & $\left.\mid \begin{array}{c}\text { 하마 } \\
\text { [hama] }\end{array}\right]$ & ᄒ ト & t \\
\hline $\begin{array}{l}\text { 아빠 } \\
\text { [ap'a] }\end{array}$ & r & 쁘 & t & $\begin{array}{l}\text { 오리 } \\
\text { [ori] }\end{array}$ & $\perp$ & ᄅ & I & $\begin{array}{l}\text { 이거 } \\
\text { [ig^] }\end{array}$ & 1 & $\neg$ & 1 & $\begin{array}{c}\text { 입어 } \\
{[\mathrm{ib} \wedge]}\end{array}$ & 1 & $\begin{array}{c}\text { 벗어 } \\
{\left[p \wedge s^{h} \wedge\right]}\end{array}$ & ㅂ & 1 & 人 1 & 1 & $\begin{array}{c}\text { 놀아 } \\
\text { [nora] }\end{array}$ & ᄂ & $\perp$ ᄅ & F & $\begin{array}{c}\text { 신어 } \\
\text { [Gin^] }\end{array}$ & ᄉ & ᄂ & ᄂ 1 & $\begin{array}{c}\text { 풀어 } \\
\text { [phurA] }\end{array}$ & 프 $T$ ᄅ & . \\
\hline 오빠 & $\perp$ & 빠 & F & $\begin{array}{l}\text { 우리 } \\
\text { [uri] }\end{array}$ & $T$ & ᄅ & 1 & $\begin{array}{c}\text { 이겨 } \\
\text { [igy^] }\end{array}$ & 1 & $\neg$ & q & $\begin{array}{c}\text { 있어 } \\
\text { [is ' } \wedge \text { ] }\end{array}$ & I $\mu$ & $\begin{array}{c}\text { 빗어 } \\
\text { [pishn] }\end{array}$ & ㅂ & I & ᄉ & 1 & $\begin{array}{c}\text { 높아 } \\
\text { [nopha] }\end{array}$ & ᄂ & $\perp$ ㅍ & F & [Dirn] & ᄉ & 12 & 21 & $\left|\begin{array}{c}\text { 불어 } \\
\text { [purn] }\end{array}\right|$ & $\forall T 2$ & 1 \\
\hline $\begin{array}{l}\text { 의사 } \\
\text { [uys } \\
\text { ana] }\end{array}$ & -1 & ᄉ & F & $\begin{array}{c}\text { 추워 } \\
\text { [ts'uw }\end{array}$ & & $T$ & \multirow{2}{*}{\multicolumn{7}{|c|}{$\begin{array}{l}\text { calculation example : } \\
2 \text { of } 3 \text { phonemes are the same, which } \\
\text { means the phonological closeness is } \\
\mathbf{2} / 3 \times 100=66 \% \text {. If the result is } 66 \% \text {, } \\
\text { it is categorized as } \mathbf{P 1} \text {. }\end{array}$}} & 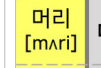 & ㅁ & 1 & ᄅ & | & $\begin{array}{c}\text { 걸어 } \\
{[\mathrm{k} \wedge \wedge \wedge]}\end{array}$ & $\neg$ & 1 ᄅ & 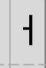 & \multirow{2}{*}{\multicolumn{7}{|c|}{$\begin{array}{c}\text { calculation example : } \\
3 \text { of } 4 \text { phonemes are the same, which } \\
\text { means the phonological closeness is } \\
\mathbf{3 / 4 \times 1 0 0}=75 \% \text {. If the result is } 75 \% \text {, } \\
\text { it categorized as } \mathbf{P 2} \text {. }\end{array}$}} \\
\hline $\begin{array}{l}\text { 의자 } \\
\text { uydza] }\end{array}$ & -1 & $\pi$ & t & $\begin{array}{c}\text { 치워 } \\
\text { [tshiwn] }\end{array}$ & & & & & & & & & & $\begin{array}{c}\text { 멀어 } \\
{[\mathrm{m} \wedge \mathrm{r} \wedge]}\end{array}$ & ㅁ & 1 & ᄅ & 1 & $\begin{array}{c}\text { 길어 } \\
\text { [kirn] }\end{array}$ & $\neg$ & I 2 & 1 & & & & & & & \\
\hline
\end{tabular}

\section{P3(80\%)}

\begin{tabular}{|c|c|c|c|c|c|c|c|c|c|c|c|c|c|c|c|c|c|c|c|c|c|c|}
\hline $\begin{array}{c}\text { 안경 } \\
\text { [angy^] }\end{array}$ & r & ᄂ & $\neg$ & F & 0 & $\begin{array}{c}\text { 달라 } \\
\text { [talla] }\end{array}$ & ᄃ & t & ᄅ & ᄅ & r & $\begin{array}{c}\text { 불러 } \\
\text { [pullı] }\end{array}$ & ᄇ & $T$ & ᄅ & ᄅ & 1 & $\begin{array}{c}\text { 빨라 } \\
\text { [p'alla] }\end{array}$ & 吅 卜 & † ᄅ & ᄅ & t \\
\hline $\begin{array}{c}\text { 안녕 } \\
\text { [anлy^n] }\end{array}$ & 1 & ᄂ & ᄂ & A & 0 & $\begin{array}{c}\text { 달려 } \\
\text { [taא^y^] }\end{array}$ & ᄃ & t & ᄅ & ᄅ & ; & $\begin{array}{c}\text { 눌러 } \\
\text { [nullı] }\end{array}$ & ᄂ & $T$ & ᄅ & ᄅ & 1 & $\begin{array}{c}\text { 발라 } \\
\text { [palla] }\end{array}$ & ㅂ & 1 ㄹ & ᄅ & t \\
\hline $\begin{array}{c}\text { 돌려 } \\
\text { [toאᄉy^] }\end{array}$ & ᄃ & $\perp$ & ᄅ & ᄅ & $\neq$ & $\begin{array}{c}\text { 남자 } \\
\text { [namdza] }\end{array}$ & ᄂ & t & ㅁ & ス & t & $\begin{array}{c}\text { 날라 } \\
\text { [nalla] }\end{array}$ & ᄂ & t & ᄅ & ᄅ & t & $\begin{array}{c}\text { 바람 } \\
\text { [param] }\end{array}$ & ㅂ & † ᄅ & r & 口 \\
\hline 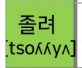 & ᄌ & $\perp$ & ᄅ & ᄅ & ; & $\begin{array}{c}\text { 감자 } \\
\text { [kamdza] }\end{array}$ & $\neg$ & t & ㅁ & ス & t & $\begin{array}{c}\text { 잘라 } \\
\text { [tsalla] }\end{array}$ & ス & f & ᄅ & ᄅ & r & $\begin{array}{c}\text { 사람 } \\
\text { [sharam] }\end{array}$ & 人 & 1 ㄹ & t & ㅁ \\
\hline $\begin{array}{c}\text { 계단 } \\
\text { kyedan] }\end{array}$ & $\neg$ & $\#$ & ᄃ & r & ᄂ & $\begin{array}{c}\text { 벌레 } \\
\text { [p^lle] }\end{array}$ & ᄇ & 1 & ᄅ & ㄹ & $\|$ & \multirow{2}{*}{\multicolumn{11}{|c|}{$\begin{array}{c}\text { calculation example : } \\
4 \text { of the } 5 \text { phonemes are the same, } \\
\text { which means the phonological closeness is } \\
4 / 5 \times 100=80 \% \text {. If the result is } 80 \% \text {, } \\
\text { it is categorized as } \mathrm{P3} \text {. }\end{array}$}} \\
\hline $\begin{array}{c}\text { 계란 } \\
\text { [kyeran] }\end{array}$ & $\neg$ & $\#$ & ㄹ & t & ᄂ & $\begin{array}{c}\text { 걸레 } \\
\text { [kAlle] }\end{array}$ & $\neg$ & 1 & ᄅ & ᄅ & $\|$ & & & & & & & & & & & \\
\hline
\end{tabular}




\section{국문초록}

\section{8-36개월 유아의 표현어휘력에 기여하는 단어의 음운유사도 양상}

양윤희 · 박수연 · 홍예은 · 이수연 · 임동선

이화여자대학교 언어병리학과

배경 및 목적: 본 연구에서는 표준화 검사인 '한국판 맥아더-베이츠 의사소통발달 평가(KM-B CDI'를 사용하여 18-36개월 유아가 지 닌 어휘를 통해 단어의 음운유사도 양상을 확인하고, 전반적인 표현어휘력을 가장 잘 설명해 줄 수 있는 음운유사도 유형은 무엇인지 살펴보고자 하였다. 방법: 연구 1 에서는 약 8 개월간의 시간 차를 두고 음운유사도 양상을 살펴보고자 하였으며, $18-36$ 개월의 총 18 명의 유아들이 T1, T2에 각각 참여하였다. 연구 2에서는 일반아동과 말늦은 아동 집단 각각에서 음운유사도가 표현어휘력을 얼마나 유의하 게 설명해 주는지 살펴보고자 하였고, 18-36개월의 총 151 명 유아들이 참여하였다. 음운유사도 점수는 두 단어 간 음운론적 공유 비율 에 따라 P1 (66\%), P2 (75\%), P3 (80\%)으로 나누었다. 결과: 연구 1에서는 18-36개월 유아의 급격한 표현어휘의 증가에도 불구하고 단어 간 음소 공유가 상대적으로 적은 P1이 일관적으로 가장 좋은 예측인자로 나타났다. 연구 2에서 TD 집단의 표현어휘력은 P1, P3, P2 순 으로 모두 유의한 설명력을 지녔으며, LT 집단의 표현어휘력은 P1이 유의한 설명요인으로 나타났다. 논의 및 결론: 적어도 만 3 세까지 는, 공유하는 음소가 더 적을 때 각 단어가 더 쉽게 구별되기 때문에 어휘를 산출할 때는 음운유사도가 상대적으로 낮은 조건이 더욱 기여도가 높을수 있음을시사한다.

핵심어: 18-36개월 유아, 음운유사도, 말늦은 아동, 표현어휘력, K M-B CDI

본 연구는 정부(교육부)의 재원으로 한국연구재단의 지원을 받아 수행된 연구임(No. NRF-2016K2A9A2A19939734).

\section{참고문헌}

김성수(2005). 낱말간 음운적 유사성이 단순언어장애 아동의 빠른 연결(fast-mapping) 수행 전략에 미치는 영향 언어청각장애연구, 10(1), 25-42. 김영태(2014). 아동언어장애의 진단 및 치료. 서울: 학지사.

배소영, 곽금주(2011). 한국판 맥아더-베이츠 의사소통발달평가(K M-B CDI). 서울: 마인드프레스.

송진영, 남기춘, 구민모(2012). 단어 빈도와음절 이웃 크기가 한국어 명사의 음성 분절에 미치는 영향 말소리와음성과학, 4(2), 3-20.

이광오, 이현진, 박현수(1995). 국어 음운 구조의 심리학적 연구: 음성분절 과정에서 음절의 효과. 인문연구, 17(1), 429-453.

장혜성, 서소정, 하지영(2011). 영아선별 교육진단검사: 전문가지침서. 서울: 학지사.

최민실, 김수진, 김효선(2014). 2세 전후반의 어휘능력과 음운능력. 유아특수교육연구, 14(1), 133-152.

하승희, 피민경(2018). 12-30개월 아동의 초기 어휘에 나타난 음운 특성. Communication Sciences \& Disorders, 23(4), 829-844.

\section{ORCID}

양윤희(https://orcid.org/0000-0003-3240-5996); 박수연(https://orcid.org/0000-0001-8675-3537);

홍예은(https://orcid.org/0000-0003-3445-3238); 이수연(https://orcid.org/0000-0002-0208-7002);

임동선(https://orcid.org/0000-0001-8254-9504) 